\title{
Threatened Egotism, Narcissism, Self-Esteem, and Direct and Displaced Aggression: Does Self-Love or Self-Hate Lead to Violence?
}

\author{
Brad J. Bushman \\ Iowa State University
}

\author{
Roy F. Baumeister \\ Case Western Reserve University
}

\begin{abstract}
It has been widely asserted that low self-esteem causes violence, but laboratory evidence is lacking, and some contrary observations have characterized aggressors as having favorable self-opinions. In 2 studies, both simple self-esteem and narcissism were measured, and then individual participants were given an opportunity to aggress against someone who had insulted them or praised them or against an innocent third person. Self-esteem proved irrelevant to aggression. The combination of narcissism and insult led to exceptionally high levels of aggression toward the source of the insult. Neither form of self-regard affected displaced aggression, which was low in general. These findings contradict the popular view that low self-esteem causes aggression and point instead toward threatened egotism as an important cause.
\end{abstract}

How do people's thoughts and feelings about themselves influence their propensities to perform acts of aggression against others? Multiple answers to this question can be suggested. For decades, clinical psychologists have subscribed to a conventional view that low self-esteem underlies aggression. Yet this is difficult to reconcile with common observations that aggressors often think very highly of themselves, as evidenced by nationalistic imperialism, "master race" ideologies, aristocratic dueling, playground bullies, and street gang rhetoric.

The present research was designed to test the opposing predictions about the link between self-views and hostile aggression. Perhaps surprisingly, the psychology of aggression lacks published laboratory experimental findings on whether self-love or self-hate contributes more to aggressive behavior. One possible reason is that many studies on aggression were conducted before trait differences in self-esteem, narcissism, and similar self-opinions became widely used in research. Alternatively, it may be that researchers have tried but failed to find a direct link. If violent acts are indeed committed by only a small subset of people with favorable self-views, then a simple measure of self-esteem might not show direct correlations with aggression.

\section{Self-Esteem, Threat, and Aggression}

In recent decades, American society has come to look on selfesteem as an unmitigated good and as a cure for a broad variety

Brad J. Bushman, Department of Psychology, lowa State University; Roy F. Baumeister, Department of Psychology, Case Western Reserve University.

We acknowledge the support of National Institutes of Health Grant MH-51482.

We thank Dan Russell for his help with the LISREL analyses and Stacy Burrell, Robin Hunn, Deanna Mackey, Tari Mellinger, Catharine Oien, Yuko Sasaki, Diane Sidari, Cassandra Skuster, Molly Steffen, and Dawn Stevenson for serving as experimenters.

Correspondence concerning this article should be addressed to Brad J. Bushman, Department of Psychology, Iowa State University, Ames, Iowa 50011-3180. Electronic mail may be sent to bushman@iastate.edu. of personal and social problems (e.g., California Task Force, 1990). Consistent with this view, it has been widely asserted that low self-esteem is a cause of violence (e.g., Kirschner, 1992; Long, 1990; Oates \& Forrest, 1985; Schoenfeld, 1988; Wiehe, 1991). According to this theory, certain people are prompted by their inner self-doubts and self-dislike to lash out against other people, possibly as a way of gaining esteem or simply because they have nothing to lose.

A contrary view was proposed by Baumeister, Smart, and Boden (1996). On the basis of an interdisciplinary review of research findings regarding violent, aggressive behavior, they proposed that violence tends to result from very positive views of self that are impugned or threatened by others. In this analysis, hostile aggression was an expression of the self's rejection of esteem-threatening evaluations received from other people. They noted that the evidence does not suggest a direct link from high self-esteem to violence, and indeed some people with high self-esteem are exceptionally nonaggressive; in general, however, aggressive people form one subset of people with highly favorable, even inflated opinions of themselves.

Stability of self-esteem may form one moderator. Kernis, Grannemann, and Barclay (1989) showed that people with high but unstable (i.e., subject to daily fluctuations) self-esteem reported the highest tendencies toward hostility and anger, whereas people with stable high self-esteem reported the lowest. High self-esteem may thus be a heterogeneous category with links to both extremes of behavior (i.e., violent and nonviolent), which could help account for the lack of published findings about selfesteem and aggression (see also Kernis, Cornell, Sun, Berry, \& Harlow, 1993). High, stable self-esteem may be indifferent or even impervious to ego threat, because one's self-love remains the same no matter what happens, and so hostility is minimal. In contrast, high but unstable self-esteem would produce heightened sensitivity to ego threats, because the individual has much to lose and is vulnerable to the miserable feeling of a brief drop in self-esteem, and so his or her sensitivity may lead to maximal hostility (see also Kernis, 1993).

Prior work thus offers competing predictions about the effects 
of self-esteem on aggression. One is that people with low selfesteem would show the highest levels of aggression. Another is that people with high self-esteem who receive an insulting or threatening evaluation would be most aggressive. A third is that the most aggressive responses would be made by a subcategory of people with high self-esteem (and in response to esteem threat). The quest for aggressive subcategories of high selfesteem brought us to the trait of narcissism, to which we now turn.

\section{Narcissism and Threatened Egotism}

Narcissism offers another approach to examining the possible link between egotism and hostile aggression. If threatened egotism is indeed the crucial cause of violence, then one may predict that vulnerability to ego threats would be the feature of selfregard most relevant to aggression. In particular, inflated, grandiose, or unjustified favorable views of self should be most prone to causing aggression, because they will encounter the most threats and be chronically most intolerant of them (Baumeister et al., 1996). These conceptions of excessive selflove are relevant to narcissism, a term coined by Freud in honor of the mythical Greek character Narcissus, who fell in love with his own image reflected in water. Although Kernberg (1975) insisted that "the nature of normal and pathological narcissism can be ascertained only by psychoanalytic exploration" ( $p$. 327 ), trait scales have been developed and have facilitated the emergence of an empirically based understanding (Emmons, 1987; Raskin \& Hall, 1979; Raskin \& Terry, 1988).

There are several possible ways to conceptualize the relationship between narcissism and self-esteem. One possibility would be that narcissism is simply an exaggerated form of self-esteem, possibly with a more emotional than cognitive character (i.e., the person may have inordinate self-love without firmly holding cognitive beliefs in his or her superior qualities). This view fits the myth of Narcissus as well as the characterization by Kohut (1971) and Kernberg (1975) of narcissism as libidinal investment in the self. A related view would be that narcissism is one subcategory of high self-esteem. In particular, it is plausible that narcissists might have inflated self-esteem, unlike other people whose high self-esteem is well founded.

Another view is that narcissism involves unstable high selfesteem, which has been linked to hostility (Kernis et al., 1989). Consistent with this last view, Rhodewalt, Madrian, and Cheney (1997) found significant correlations between narcissism and instability of self-esteem, although the correlations were not so high as to indicate that the two are the same. Moreover, their data linked narcissism more strongly to instability of self-esteem than to high self-esteem per se.

Correlations between narcissism and self-esteem have varied substantially across studies, making it necessary to consider the possibility that there are some narcissists with low self-esteem. According to analyses by Kohut (1971) and Kernberg (1975), there are at least two ways that a narcissist could score low in self-esteem. One is that the narcissist may be defensive, so he or she develops a veneer of high self-regard that is nonetheless hollow or brittle because it conceals underlying feelings of insecurity and low self-esteem. The other is that the narcissistic self-love may be an emotional, immature holdover from early development, so the person may remain emotionally invested in a grandiose self-image despite also having developed a less favorable (and presumably more accurate) self-appraisal. In effect, the person holds two unrelated sets of views about the self, possibly with the aid of unconscious processes or dissociations, so that "haughty grandiosity, shyness, and feelings of inferiority may co-exist in narcissistic personalities without affecting each other"' (Kernberg, 1975, p. 331).

In a sense, then, narcissism may be less a matter of having a firm conviction about one's overall goodness (which is selfesteem in a literal sense) than a matter of being emotionally invested in establishing one's superiority. It may, in other words, be more a matter of motivation and emotion than of cognition per se: Narcissists care passionately about being superior to others, even if they are not yet convinced that they have achieved this superiority. Hence, high or low levels of narcissism could be found together with either high or low self-esteem. This view resembles the one suggested by Raskin, Novacek, and Hogan (1991) and Morf and Rhodewalt (1993), who focused on narcissism as an attempt to regulate self-esteem. The social behavior of narcissists may be geared toward maximizing self-esteem (e.g., by gaining the approval and admiration of others ) as part of the quest to validate their grandiose self-image.

There is ample reason to suggest that narcissism could be associated with increased aggression, especially in response to insults or other negative evaluations. On theoretical and clinical grounds, Kernberg (1975) proposed that narcissism includes patterns of rage that began in response to parental rejection, and rejection by others during adulthood could reactivate that rage. Millon (1981) proposed, contrary to Kernberg's view, that narcissism stems from an individual having parents who overvalued him or her as a child and instilled an inflated sense of entitlement and deservingness, which clearly could generate rage whenever events fail to confirm this inflated sense. Such aggressive responses seem parallel to patterns of shame-based rage that have recently been demonstrated (Tangney, 1995; Tangney, Wagner, Fletcher, \& Gramzow, 1992). Kernberg (1975) observed that narcissists seem inordinately sensitive to slight insults or criticism, and they are prone to react with hostility.

Questionnaire studies have yielded some positive correlations between narcissism and aggressiveness or hostility (Raskin et al., 1991; Wink, 1991). Emmons (1987) linked narcissism to extreme emotional lability and strong reactions, which could well include anger and rage that might increase aggressive tendencies. Rhodewalt and Morf (1995) found a significant correlation between narcissism and hostility. In a subsequent work, Rhodewalt and Morf (in press) showed that, when initial success was followed by failure feedback, narcissists became exceptionally angry, in part because they made internal attributions for the success and then presumably believed that these flattering conclusions about themselves were jeopardized by the subsequent failure. Meanwhile, some factors that normally restrain aggression also seem to be deficient in narcissists, insofar as narcissism is correlated with disinhibiting tendencies (Emmons, 1984) and low empathy (Watson, Grisham, Trotter, \& Biderman, 1984). All of these findings suggest that aggression should be high among narcissists, particularly when their anger is provoked by criticism or any other esteem threat. 


\section{Threat, Displacement, and Predictions}

The main prediction for the present research was that the combination of high narcissism and ego threat would lead to exceptionally high levels of aggression. That is, narcissists who received negative interpersonal feedback would be strongly inclined to respond with aggression toward the source of this feedback.

Although this was the main prediction, several additional hypotheses and theoretical issues were investigated. We included both self-esteem and narcissism and allowed the two variables to compete against each other to predict aggression. First, we sought to examine whether self-esteem would contribute directly to aggressive responding. As already noted, the traditional view in psychology is that low self-esteem causes aggression, and so this view would predict higher levels of aggression among people scoring low in self-esteem. This effect could well be independent of all other factors. The opposite view, that aggression will be highest among people high in self-esteem, is also plausible.

A second issue was whether any effects of narcissism or selfesteem would be confined to responses to ego threat. Narcissism is characterized by feelings of superiority over other people, and so simple disregard for the rights and feelings of others could result in higher aggression, even in the absence of threat. It is also plausible that narcissists perceive social life as a series of struggles for dominance, and so they may attack others regardless of direct threat, simply as a means of establishing themselves in a superior position by conquering or intimidating other individuals. In the present studies, participants found themselves in the position of being evaluated by another person, which implies a position of vulnerability and dependency. Later, they also found themselves in a direct competition with someone (who was either the evaluator or a different person). Either of these circumstances might cause narcissists to attempt to assert their own superiority through aggressive action.

Likewise, if low self-esteem engenders a desire to rise above others by attacking them, it could occur in any competitive situation. Hence, the traditional view might predict a main effect by which low self-esteem leads to high aggression, regardless of situational factors. Alternatively, the situations of evaluative dependency or competition could elicit aggression from people with low self-esteem.

A third issue is displaced aggression. Theories about aggression have varied widely in the degree to which they emphasize the interpersonal aspect. To caricature slightly, these theories have ranged from treating aggression as an eruption of intrapsychic forces (in which case the choice of target is almost irrelevant) to treating it as a form of interpersonal communication (cf. Berkowitz, 1989; Dollard, Doob, Miller, Mowrer, \& Sears, 1939; Tedeschi \& Felson, 1994). In Study 2, we examined aggression toward the source of the insulting evaluation and aggression toward an innocent third person. If aggression results from ego threat simply because bad moods or other inner processes create aggressive impulses (or remove the barriers to instinctive aggressive impulses), then aggression should be high regardless of the target. In contrast, if aggression is a means of communicating directly with the evaluator, then there should be no increase in aggression toward the innocent third person, even if the participant received a severe blow to his or her self-esteem.

We have used the terms violence and aggression somewhat interchangeably in this introduction. Strictly speaking, our laboratory procedures measure aggression but not violence, insofar as the latter is limited to acts that cause serious harm to victims. Nonetheless, it is generally assumed that the study of laboratory aggression can shed light on the causes of violence outside the laboratory. In support of this view, Anderson and Bushman (1997) have reviewed evidence that laboratory findings generalize well to nonlaboratory situations.

\section{Study 1}

Study 1 was a direct test of the main hypothesis that threatened egotism would lead to maximal aggression. We measured both narcissism and self-esteem, exposed participants to an evaluation that constituted either an ego threat or an ego boost, and then measured aggression toward the person who had delivered the evaluation.

\section{Method}

Trait measures. Self-esteem was measured via the standard scale developed by Rosenberg (1965), a widely used instrument with good psychometric properties. Sample items are "I feel that I have a number of good qualities," "I take a positive attitude toward myself," and "I am able to do things as well as most people." Each item is answered on a 7-point scale, and responses are summed to create a global selfesteem score, with high scores indicating high self-esteem. Narcissism was measured with the Narcissistic Personality Inventory (Raskin \& Terry, 1988), which has excellent psychometric properties. The scale contains 40 items that are answered by means of a simple true-false format. Sample items from the scale are "If I ruled the world it would be a much better place," "I am going to be a great person," and "I am more capable than other people." In the present sample, the alpha coefficients for the self-esteem and narcissism scales were .55 and .78 , respectively. The correlation between the two scales was $.09(p>.05)$. Self-esteem scores were higher for men $(M=35.3, S D=4.6)$ than for women $(M=34.1, S D=3.3), t(258)=2.30, p<.05, d=0.30$. Narcissism scores also were higher for men $(M=19.5, S D=5.8)$ than for women $(M=17.4, S D=5.1), t(258)=3.14, p<.05, d=0.35$.

Participants. Participants were 266 undergraduate psychology students (132 men and 134 women) who received extra course credit in exchange for their voluntary participation. Participants were selected randomly from a large pool of students who had completed the selfesteem scale as part of a battery of questionnaires given in mass-testing sessions. The data for 6 participants were discarded as a result of these individuals' suspiciousness or failure to follow instructions. The final sample consisted of 260 participants ( 130 men and 130 women). Also, a separate sample of 10 men and 10 women took part in a manipulation validation study.

Procedure. Experimental participants were tested individually in the laboratory session, but each was led to believe that he or she would be interacting with someone else of the same sex. Participants were told that the researchers were studying how people react to positive and negative feedback. Informed consent was obtained after the participant had been told that the experiment would involve writing essays and then competing on a reaction time task with stressful, noisy stimuli as a possible outcome. After informed consent had been obtained, the participant completed the narcissism scale. The participant was told that the scale was being used to determine whether feedback affects different types of people in different ways. 
Each participant was asked to write a one-paragraph essay on abortion, either pro-choice or pro-life (whichever the participant preferred). After completion, the participant's essay was taken away to be shown to the other participant (who was, in fact, nonexistent) for evaluation. Meanwhile, the participant was permitted to evaluate the partner's essay, which, by random assignment, was either a pro-choice or a pro-life essay. There was one essay of each type, and every participant saw one or the other. We also controlled for handwriting by having male and female versions of the standard essays. (Which essay the participant saw had no effect on subsequent aggressive behavior, which rules out any explanation that aggression was mediated by perceptions of partner attitude or of similarity between participant and partner.)

A short time later, the experimenter returned the participant's own essay with comments ostensibly made by the other participant. These comments constituted the experimental manipulation of ego threat. By the flip of a coin, half of the participants were assigned to the ego threat condition, and they received bad evaluations consisting of negative ratings on organization, originality, writing style, clarity of expression, persuasiveness of arguments, and overall quality. There was also a handwritten comment stating "This is one of the worst essays I have read!" The other participants received favorable, positive evaluations consisting of high (positive) numerical ratings and the following written comment: "No suggestions, great essay!"

The next part of the procedure was presented as a competitive reaction time task based on a paradigm developed by Taylor (1967). ${ }^{1}$ Previous studies have established the construct validity of Taylor's paradigm (e.g., Bernstein, Richardson, \& Hammock, 1987; Giancola \& Zeichner, 1995). The participant was told that he or she and the partner would have to press a button as fast as possible on each trial and that whoever was slower would receive a blast of noise. Each participant was permitted to set in advance the intensity of the noise that the other person would receive between $60 \mathrm{~dB}$ (Level 1) and $105 \mathrm{~dB}$ (Level 10) if the other lost. A nonaggressive no-noise setting (Level 0 ) was also offered. In addition to determining noise intensity, the winner determined the duration of the loser's suffering, because the duration of the noise depended on how long the winner held the button pressed down. In effect, each participant controlled a weapon that could be used to blast the other person if the participant won the competition to react faster.

A Macintosh II computer controlled the events in the reaction time task and recorded the noise levels and noise durations the participant set for the "other person." The white noise consisted of sound files synthesized by a digital waveform editor (Farallon Soundedit 2.0.5) and reproduced through an Audiomedia 2.0 Digidesign 16-bit digit-to-analog converter. The analog output was amplified by an NAD 3225PE integrated amplifier and delivered through a pair of Telephonics TDH-39P headphones. A General Radio 156-B sound level meter was used to calibrate the noise levels.

After completion of the reaction time task, the participant was debriefed and dismissed. A separate sample of participants took part in a validation study to check the ego threat manipulation (see later discussion).

\section{Results}

Manipulation validation. To verify the impact of the ego threat manipulation, we conducted a pilot study. As mentioned earlier, 10 men and 10 women took part. They followed the same procedure of writing the essay and receiving either the favorable or unfavorable evaluation. Instead of continuing on to the aggression measure, however, participants completed a questionnaire assessing how they felt on receiving the evaluation and how they perceived the evaluation.

All effects were large and significant. The bad evaluation of the participant's essay, in comparison with the good evaluation, was rated as more threatening, $t(18)=2.19, p<.05, d=0.98$; more malicious, $t(18)=4.94, p<.05, d=2.21$; and less fair, $t(18)=-5.08, p<.05, d=2.29$. Also, participants receiving the bad evaluation (relative to those receiving the good evaluation) reported that it lowered their self-esteem, $t(18)=3.05$, $p<.05, d=1.36$, and made them feel angry, $t(18)=2.21, p$ $<.05, d=0.99$. These results confirm that the bad evaluation procedure did indeed constitute an upsetting ego threat.

Main analysis strategy. Noise intensity and noise duration were measures of the same construct: aggressive behavior. The same pattern of results was obtained for both measures, and the two measures were significantly correlated $(r=.32) .^{2}$ As a means of creating a more reliable measure, the noise intensity and noise duration data were standardized and summed to form a total measure of aggressive behavior.

The data were analyzed via regression analysis. In regression analysis, researchers recommend centering the predictor variables when testing for interaction effects (e.g., Aiken \& West, 1991; Jaccard, Turrsi, \& Wan, 1990). This transformation, which reduces the correlation between the product term and the component parts of the term, was used in the present analyses. The regression model included main effects for ego threat ( $1=$ present, $0=$ absent), narcissism (continuous), self-esteem (continuous), and $\operatorname{sex}(1=$ male, $0=$ female $)$. The model also included two-way and three-way interactions, which were computed as multiplicative products of the main effects. A hierarchical analysis of sets approach was used (Cohen \& Cohen, 1983). The main effects were entered in the first step, the twoway interactions were entered in the second step, and the threeway interactions were entered in the third step. The four-way interaction was added to the error term. Thus, the main effects were removed from the two-way interactions, and the main

\footnotetext{
${ }^{1}$ The reaction time task consisted of 25 trials. After the initial (no provocation) trial, the remaining 24 trials were divided into three blocks of 8 trials each. The participant received feedback on the intensity of noise the "opponent" set on each trial. Provocation was manipulated by increasing the intensity and duration of noise blasts the "other person" set for the participant across trials. In this article, we describe only the results of Trial 1 aggression. Responses on the first trial provided the best measure of unprovoked aggression, because the participant had not yet received noise or feedback from the "other person." After the first trial, aggression converged on reciprocation of what the partner had ostensibly done. This is consistent with many previous findings suggesting that reciprocation is a powerful norm in determining aggressive responses during an ongoing aggressive exchange. Only a few other significant effects were found on subsequent trials. In Study 1, men were more aggressive than women, $F(1,245)=19.93, p<.05, d=0.57$. In Study 2, there was a main effect for aggression target that was qualified by an interaction between threat and aggression target, $F \mathrm{~s}(1$, $254)=4.08$ and 5.05 , respectively, $p s<.05$. Participants who received a bad evaluation were more aggressive than those who received a good evaluation when the target was the source of the evaluation but not when the target was an innocent third party.

${ }^{2}$ The regression analysis for noise intensity revealed main effects for threat, narcissism, and sex, $F \mathrm{~s}(1,245)=7.79,11.72$, and 23.63, respectively, $p \mathrm{~s}<.05$. The regression analysis for noise duration revealed a main effect for narcissism and a nearly significant interaction between narcissism and ego threat, $F(1,245)=4.08, p<.05$, and $F(1,245)=3.27, p<.10$, respectively.
} 
effects and two-way interactions were removed from the threeway interactions.

Multicollinearity, or correlation among the predictor variables, was tested by means of variance inflation factors (VIFs; e.g., Neter, Wasserman, \& Kutner, 1990). A VIF of 1 indicates that the model terms are not linearly related. A maximum VIF value in excess of 10 is often taken as an indication that multicollinearity may be unduly influencing the least squares estimates. The maximum VIF in the regression analyses for Study 1 was 1.1 , indicating that multicollinearity was not a problem.

Aggression. The regression analysis yielded significant main effects for ego threat, narcissism, and sex. Ego threat in the form of insulting evaluation of the essay led to higher aggression than the nonthreatening, favorable evaluation, $F(1,245)$ $=4.41, p<.05, b=0.39, S E=0.19, d=0.25$. There was a positive relation between narcissism and aggression, $F(1,245)$ $=13.92, p<.05, b=0.06, S E=0.02, r=.27$. Also, men were more aggressive than women, $F(1,245)=14.54, p<$ $.05, b=0.71, S E=0.19, d=0.56$.

More important, there was an interaction between narcissism and ego threat, $F(1,245)=5.04, p<.05, b=0.08, S E=$ 0.03 . This interaction, depicted in Figure 1, indicated that (high) narcissists who received the ego threat were exceptionally aggressive, even above and beyond what would be expected on the basis of the simple additive combination of the two variables. In Figure 1, different regression lines are plotted for ego threat and praise feedback for the range of narcissism scores obtained in the study ( see Aiken \& West, 1991). This interaction confirmed the main hypothesis regarding the effects of narcissism and ego threat on aggression. As can be seen in Figure 1, the relation between narcissism and aggression was stronger when the evaluation was negative than when it was positive, $F(1$, $245)=20.36, p<.05, b=0.11, S E=0.02, r=.37$, and $F(1$, $245)=4.59, p<.05, b=0.05, S E=0.02, r=.18$, respectively. Still, the effect of narcissism on aggression remained significant even when the evaluation was positive.

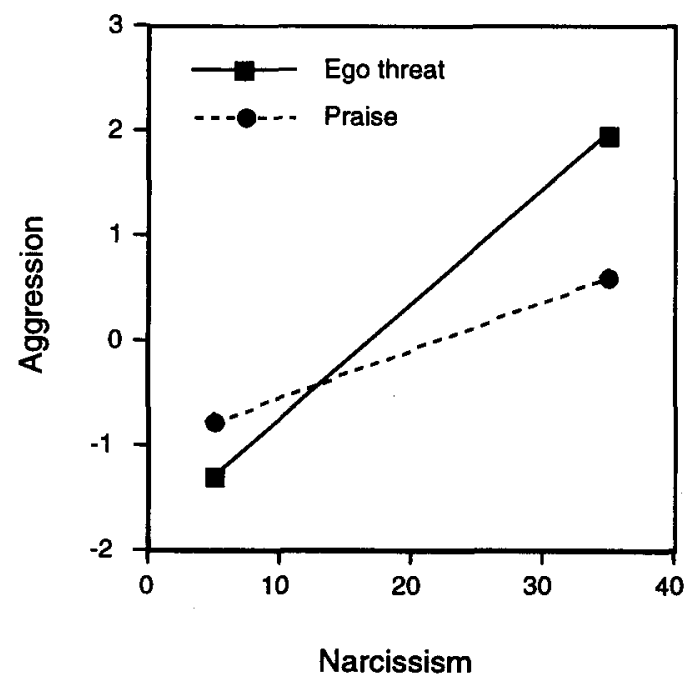

Figure 1. Relation between narcissism and aggression for participants who received either a positive or negative evaluation.
When only the main effects were included in the model, the $R^{2}$ value was .14 . When the two-way interactions were added, the model $R^{2}$ value was .16 (i.e., it increased by .02 ), and when the three-way interactions were added, the value was .17 (i.e., it increased by an additional .01 ).

The Narcissistic Personality Inventory includes between four (Emmons, 1987) and seven (Raskin \& Terry, 1988) subscales. In the present study, the total scale was more strongly related to aggression than any of the subscales.

Self-esteem was allowed to compete with narcissism to predict aggression. But self-esteem was not related to aggression, either alone or in interaction with other variables. Additional analyses were conducted in which narcissism was excluded as a predictor. Even in these analyses, no significant effects involving self-esteem were found.

\section{Discussion}

Study 1 found that ego threats in the form of insulting, negative evaluations increased aggressive responding for all types of individuals, as suggested by many prior findings (for reviews, see Baron \& Richardson, 1993; Geen, 1990). More important, these aggressive responses were strongest among people who scored high in narcissism. Thus, the highest levels of aggression were found among people who have emotional and motivational investment in extremely favorable, grandiose self-images. These results are consistent with the view that threatened egotism is a particular cause of aggression and violence.

It is also noteworthy that narcissism led to increased aggression independently of ego threat, as indicated by a main effect. Put another way, narcissists were aggressive even toward someone who had evaluated them favorably. As noted in the introduction, there are several possible reasons for this effect, although we believed that replication was desirable before drawing strong conclusions. Study 2 was conducted in part to ascertain whether narcissists would show increased aggression toward a third person who had not evaluated them at all.

Self-esteem yielded no significant effects, either independently or in interaction with other variables. The lack of effects contradicts the traditional view that low self-esteem causes aggression, as well as any suggestion that favorable self-views in general lead to aggression (including in combination with ego threat). The standard view is that null findings are uninterpretable; in this case, however, the fact that the narcissism scale yielded both a significant main effect and a significant interaction makes the failure of the self-esteem measure seem more conclusive.

Still, before self-esteem is dismissed as irrelevant to aggression, several potential drawbacks must be noted. First, the selfesteem measure was given in mass-testing sessions some weeks before the laboratory session, and so its predictive power might have been somewhat weaker than that of the narcissism scale, which was given at the same experimental session as the dependent measures. Second, the alpha coefficient (.55) for the Rosenberg scale was unacceptably low in this sample. Although that scale is often regarded as having good psychometric properties, it emphatically did not have them here, possibly because students participating in the group testing session failed to respond 
to it as carefully, thoughtfully, or honestly as respondents in other settings might.

Third, it is possible that the Rosenberg scale is insensitive to relevant differences. It is, in fact, a relatively short, simple, and obvious measure of self-esteem. Perhaps surprisingly, there was no significant correlation between the self-esteem and narcissism scales $(r=.09)$, and one would expect that narcissism should correlate with self-esteem (on the basis of both a priori reasoning and previous findings; Kernberg, 1975; Rhodewalt et al., 1997). Thus, the lack of correlation raises further suspicion about the efficacy of the scale as used here.

Our results do dovetail with those of Kernis et al. (1989) to suggest that self-esteem, as measured by the Rosenberg scale, does not have any such direct link to aggression and that the most aggressive people are likely to be one subset of individuals with highly favorable opinions of themselves. In any case, it seemed desirable to use a different self-esteem measure in Study 2 .

\section{Study 2}

Our second experiment had several purposes. First, it seemed desirable to replicate the effects of narcissism and ego threat found in Study 1. Second, we wanted to try a different measure of self-esteem to determine whether it might have more success in yielding significant effects than the scale used in Study 1.

Third, it seemed desirable to investigate aggression toward someone other than the evaluator. Study 1 revealed that narcissists were more aggressive than others toward someone who criticized them. They were also more aggressive, although by a smaller margin, toward someone who had praised them. Thus, narcissism seems to foster aggressive responses to evaluation, regardless of the valence of that evaluation. One possible view is that narcissists are simply more aggressive toward everyone, in which case aggression toward a third person would be higher than that of nonnarcissists. Alternatively, it may be that submitting to evaluation is inherently threatening to narcissists, given their overriding sense of superiority, and so they aggress only toward people who evaluate them.

\section{Method}

Trait measures. In Study 2, participants completed the Narcissistic Personality Inventory (Raskin \& Terry, 1988). The alpha coefficient for the scale was .80 . Narcissism scores were significantly higher for men $(M=20.0, S D=6.5)$ than for women $(M=18.5, S D=5.7), t(278)$ $=2.00, p<.05, d=0.24$.

To measure self-esteem, we used a version of the Janis and Field (1959) scale. This scale has been widely used to measure self-esteem. Fleming and Courtney (1984) produced a recent version that has been influential. Following Baumeister's usual procedure (e.g., Baumeister, Heatherton, \& Tice, 1993), we administered only the first three subscales, which measure global self-regard, academic-task esteem, and social self-esteem. This version of the scale contains 26 items that are answered in a 7-point response format. Sample items from the scale are "How often do you dislike yourself?" "In general, how confident do you feel about your abilities?" and "How confident do you feel that someday the people you know will look up to you and respect you?'" The alpha coefficient for the self-esteem scale was .93. Self-esteem scores were significantly higher for men $(M=123.8, S D=22.5)$ than for women $(M=117.8, S D=25.3), t(278)=2.12, p<.05, d=$
0.25. Unlike the Rosenberg (1965) scale used in Study 1, this selfesteem scale did yield a significant correlation with narcissism $(r=$ $.33, p<.05)$.

Participants. Participants were 281 undergraduate psychology students (141 men and 140 women) who received extra course credit in exchange for their voluntary participation. The data for 1 participant were discarded because he expressed suspicion about the procedure. The final sample consisted of 280 participants ( 140 men and 140 women).

Procedure. The procedure for Study 2 was the same as the procedure for Study 1, with four exceptions. First, participants completed the selfesteem scale as well as the narcissism scale in the laboratory. Second, the ostensible partner's essay was controlled so that it always agreed with the attitudinal position that the participant advocated. That is, if the participant wrote a pro-choice essay, then he or she evaluated a prochoice essay; if the participant wrote a pro-life essay, then he or she evaluated a pro-life essay. This procedure modification allowed us to completely rule out the possibility that aggression was mediated by perceptions of partner attitude or of similarity between participant and partner. Third, the participant rated how threatening the essay evaluation was. Several other ratings were included as fillers. Ratings were made along a 10-point Likert-type scale ranging from 1 (strongly disagree) to 10 (strongly agree). The ratings were used to test whether threat mediated the relation between narcissism and aggression. Fourth, by the flip of a coin, the partner on the reaction time task was said to be either the same person who evaluated the participant's essay (direct aggression) or a different person (displaced aggression).

\section{Results}

Analysis strategy. As in Study 1, the noise intensity and noise duration data were standardized and summed to form a more reliable measure of aggressive behavior. ${ }^{3}$ Also as in Study 1 , the predictor variables were centered for the regression analysis. The regression model included main effects for ego threat ( $1=$ present, $0=$ absent $)$, aggression target ( $1=$ direct aggression, $0=$ displaced aggression), narcissism (continuous), selfesteem (continuous), and $\operatorname{sex}(1=$ male, $0=$ female). The model also included two-way and three-way interactions. The interaction between threat and aggression target was predicted to be of a spreading type rather than a crossover type. Specifically, higher levels of aggression were expected for participants who received a negative evaluation and then aggressed directly against the person who provided the evaluation (coded as 3 ) than for participants in the other three groups (each coded as -1 ). This coding also was used for any three-way interactions that included threat and aggression target. As in Study 1, a hierarchical analysis of sets approach was used (Cohen \& Cohen, 1983). The main effects were entered in the first step, the two-way interactions were entered in the second step, and the three-way interactions were entered in the third step. Higher order interactions were added to the error term. Multicollinearity was tested by means of VIFs. The maximum VIF in the regression analyses for Study 2 was 4.2 , indicating that multicollinearity was not a problem (Neter et al., 1990).

\footnotetext{
${ }^{3}$ The regression analyses for noise intensity revealed a Threat $x$ Aggression Target interaction and a Threat $\times$ Sex interaction, $F \mathrm{~s}(1$, $254)=9.75$ and 4.59 , respectively, $p s<.05$. The regression analysis for noise duration revealed a Threat $\times$ Aggression Target interaction and a nearly significant Threat $\times$ Aggression Target $\times$ Narcissism interaction, $F(1,254)=5.35, p<.05$, and $F(1,254)=2.66, p<.11$, respectively.
} 
Manipulation validation. To verify the impact of the ego threat manipulation, we analyzed ratings of how threatening participants thought the evaluation was. All variables were entered in the regression model except those involving aggression target, which was manipulated after participants had rated the evaluations. As expected, the negative evaluation was judged to be more threatening than was the positive evaluation, $F(1,263)$ $=124.79, p<.05, d=1.46$. No other significant effects were found.

Aggression. The predicted three-way Ego Threat $\times$ Aggression Target $\times$ Narcissism interaction was nearly significant, $F(1,254)=2.89, p<.10, b=0.03, S E=0.02$. Narcissism was positively related to direct aggression when the evaluation was bad, but it was unrelated to direct aggression when the evaluation was good, $F(1,254)=9.62, p<.05, b=0.09, S E$ $=0.04, r=.25$, and $F(1,254)=0.34, p>.05, b=-0.02$, $S E=0.02, r=-.10$, respectively (see left portion of Figure 2 ). Meanwhile, narcissism was unrelated to displaced aggression, regardless of whether the evaluation was bad or good, $F(1$, 254) $=0.99, p>.05, b=0.02, S E=0.02, r=.14$, and $F(1$, 254) $=0.61, p>.05, b=0.02, S E=0.03, r=.10$, respectively (see right portion of Figure 2).

Other significant effects less central to the hypotheses were found. There was a main effect for aggression target, $F(1,254)$ $=5.89, p<.05, b=0.65, S E=0.03, d=0.27$. This main effect, however, was qualified by an interaction between evaluation type and aggression target, $F(1,254)=13.63, p<.05, b=0.33$, $S E=0.09$. Participants who received a bad evaluation were more aggressive than those who received a good evaluation when the target was the source of the evaluation, but not when the target was an innocent third party, $F(1,254)=39.72, p<$ $.05, d=0.93$, and $F(1,254)=1.75, p>.05, d=0.25$, respectively. These findings support the view of aggression as retaliation for a bad evaluation: People were most aggressive toward the person who insulted them.

When only the main effects were included in the model, the $R^{2}$ value was .10. When the two-way interactions were added, the model $R^{2}$ value was .19 (i.e., it increased by .09 ), and when the three-way interactions were added, the value was .24 (i.e., it increased by an additional .05 ).

Given the theoretical questions about what aspect of narcissism leads to aggression, we repeated the main analyses using the various subscales of the Narcissistic Personality Inventory in place of the grand total. These subscale analyses yielded little useful information and generally offered simply weaker versions of the same results that the total score gave. The total score was more strongly related to aggression than any of its subscales.

As in Study 1, self-esteem was allowed to compete with narcissism to predict aggression. But self-esteem was not related to aggression, either alone or in interaction with other variables. Even in additional analyses that excluded narcissism as a predictor, no significant effects involving self-esteem were found.

Threat as mediator. Recall that participants in Study 2 rated the evaluation they had received in terms of its level of threat. We used this rating to measure perceived threat. An analysis was conducted to test whether perceived threat mediated the relation between narcissism and aggression in the condition in which participants received a negative evaluation on their essay and then aggressed directly against the same person who had evaluated them (i.e., the ego threat-direct aggression condition ). For the other three conditions, it was predicted that narcissism, perceived threat, and aggression would be unrelated to one another. Table 1 shows the variance-covariance matrices.

As a means of testing this model, a multiple group analysis was conducted with the LISREL 8 computer program (Jöreskog \& Sörbom, 1993). For participants in the ego threatdirect aggression condition, a causal path was specified from narcissism to perceived threat, and another causal path was specified from perceived threat to aggression. For participants in the other three conditions, these two causal paths were fixed at zero. The hypothesized model provided a very good fit to the data, $\chi^{2}(10, N=280)=7.87, p=.64$, goodness of fit index $=$ .98 , comparative fit index $=1.00$, root mean square error of approximation $=0.0$. For participants in the ego threat-direct
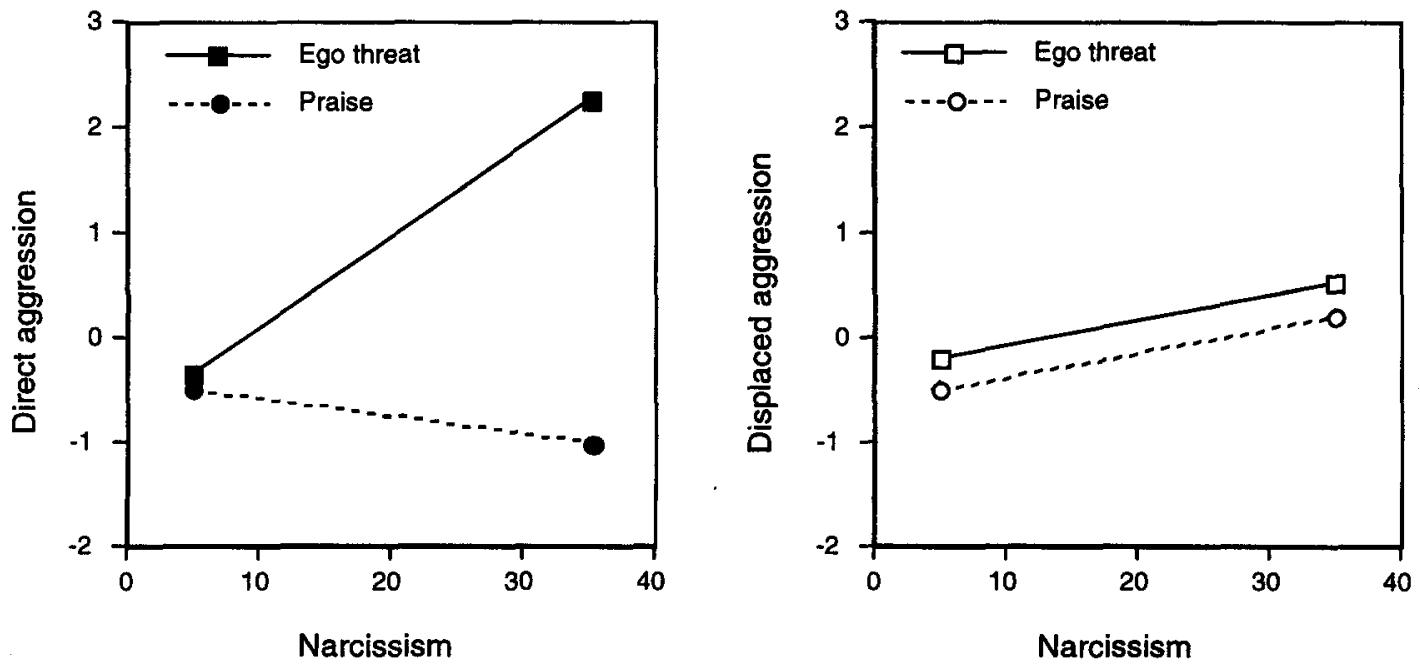

Figure 2. Relation between narcissism and direct and displaced aggression for participants who received either a positive or negative evaluation. 
Table 1

Data for the LISREL Analysis

\begin{tabular}{|c|c|c|c|c|c|}
\hline Measure & 1 & 2 & 3 & $M$ & $S D$ \\
\hline \multicolumn{6}{|c|}{ Ego threat-direct aggression condition } \\
\hline 1. Narcissism & 36.03 & 6.16 & 3.12 & 17.87 & 6.00 \\
\hline 2. Perceived threat of evaluation & $.33 *$ & 9.46 & 1.51 & 4.04 & 3.08 \\
\hline 3. Aggression & $.25 *$ & $.24 *$ & 4.18 & 0.74 & 2.04 \\
\hline \multicolumn{6}{|c|}{ Ego threat-displaced aggression condition } \\
\hline 1. Narcissism & 47.13 & -3.02 & 1.15 & 20.08 & 6.86 \\
\hline 2. Perceived threat of evaluation & -.15 & 8.97 & 0.17 & 4.99 & 3.00 \\
\hline 3. Aggression & .15 & .05 & 1.39 & 0.16 & 1.18 \\
\hline \multicolumn{6}{|c|}{ Praise-direct aggression condition } \\
\hline 1. Narcissism & 33.02 & 0.12 & -0.56 & 18.71 & 5.75 \\
\hline 2. Perceived threat of evaluation & .02 & 0.95 & 0.06 & 1.26 & 0.97 \\
\hline 3. Aggression & -.10 & .06 & 0.99 & -0.74 & 0.99 \\
\hline \multicolumn{6}{|c|}{ Praise-displaced aggression condition } \\
\hline 1. Narcissism & 30.37 & 0.21 & 0.72 & 20.34 & 5.51 \\
\hline 2. Perceived threat of evaluation & .06 & 0.39 & -0.03 & 1.20 & 0.63 \\
\hline 3. Aggression & .10 & -.04 & 1.72 & -0.16 & 1.31 \\
\hline
\end{tabular}

Note. Variances are on the diagonal, and covariances are above the diagonal. Correlations are reported below the diagonal for descriptive purposes. $n=70$ in each condition.

${ }^{*} p<.05$.

aggression condition, the causal path from narcissism to perceived threat was positive and significant, as was the causal path from perceived threat to aggression (see Figure 3).

To examine the effect of constraining these two causal paths to zero for the other three conditions, we tested a second model wherein the two paths were specified as free parameters for all four conditions. The fit of this latter model was found to not be significantly better than the fit of the hypothesized model, $\chi^{2}(4$, $N=280)=5.56, p=.23$. These results indicate that narcissism, perceived threat, and aggression were unrelated to one another in the other three conditions.

The results of these analyses provide support for the mediation model. However, it is also possible that narcissism had a direct effect on aggression among participants in the ego threatdirect aggression condition. To evaluate this possibility, we tested a second modification of the hypothesized model wherein the causal path from narcissism to aggression was included as a free parameter. Once again, inclusion of this parameter did not lead to a significant improvement in the fit of the model to the data, $\chi^{2}(1, N=280)=2.55, p=.11$. Thus, the direct causal path from narcissism to aggression was nonsignificant
( $z=1.61, p=.11$ ). In summary, these analyses suggest that narcissists aggress directly against individuals who give them negative feedback because they view the feedback as a threat to their ego.

\section{Discussion}

Several important findings emerged from Study 2. We replicated the key findings of Study 1 , in that high narcissism increased aggression overall and led to especially high aggression in direct response to the bad, threatening evaluation. The apparent links between narcissism and aggressive behavior were thus confirmed.

We also replicated the null results of Study 1 in terms of absence of self-esteem effects. That Study 2 measured selfesteem in the same session as the aggression measure and used a different self-esteem scale from Study 1 would seemingly rule out some of the possible explanations for the null results of Study 1 and cast further doubt on the direct relevance of selfesteem to aggressive behavior in this sort of setting.

Not all findings of Study 1 were replicated. In Study 2, narcis-

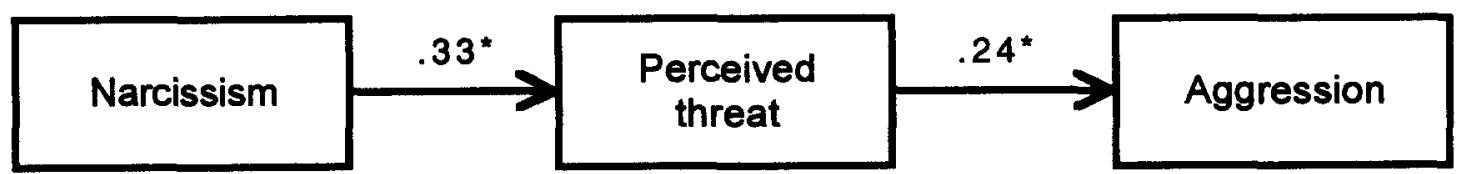

Figure 3. Threat as a mediator between narcissism and direct aggression for participants who received a negative evaluation. ${ }^{*} p<.05$. 
sism did not have a significant effect on aggression in response to the good evaluation. Put another way, in Study 1 narcissists were aggressive even toward the person who praised them, but this effect did not replicate in Study 2.

Study 2 was not confined to replication. We included an aggressive target manipulation that permitted comparison between direct and displaced aggression. Narcissism showed no relation to aggression toward a third person (who had not delivered an evaluation). Combined with the failure to replicate greater aggression by narcissists toward the positive evaluator, this finding suggests that narcissists are fairly selective and specific in their aggression. The seeming implication of Study 1 that narcissism increases aggression toward everyone should probably be discarded.

These results can be interpreted in the following way. Narcissism did indeed enhance the tendency to respond aggressively to a bad evaluation, and so narcissists' aggression was high toward the source of this evaluation (but not toward anyone else). When someone praised the narcissist, on the other hand, the narcissist did not show elevated aggression. Narcissism did not alter the level of aggression toward a new person. The most consistent interpretation is that narcissists were exceptionally aggressive toward anyone who attacked or offended them. Otherwise, their aggression did not differ from that of other people.

Our mediation analysis confirmed that perceptions of threat did mediate between narcissism and aggression. The more a narcissist perceived the bad evaluation as threatening, the more aggressively he or she behaved. People who scored low in narcissism, in contrast, were less likely to perceive the evaluation as threatening, and these lower perceptions of threat led to lower aggression.

\section{General Discussion}

The present investigation has confirmed important links between self-appraisal and aggression. Some theorists have proposed that people with low self-esteem would be most likely to lash out in response to an ego threat because the unflattering evaluation reminds them of their personal flaws and faults or because their low self-esteem makes them unable to tolerate the prospect of losing any of it. Others might suggest that low selfesteem would cause an increase in aggression regardless of ego threat. Our results contradict such views.

Instead, it appears that people who are emotionally invested in grandiose self-views are the most aggressive, particularly in response to an esteem threat. In both studies, we found that narcissism combined with ego threat yielded the highest levels of aggression. The combination of narcissism and ego threat was the primary focus of our investigation. Thus, the most aggressive responding in both studies was found among narcissists who were attacking someone who had given them a bad evaluation. These people were significantly more aggressive than would be predicted simply by adding any broad (main) effects of narcissism and ego threat. Moreover, the mediation analyses of Study 2 confirmed that degree of perceived threat determined level of aggression.

Our results also shed light on whether narcissists are more hostile and aggressive in general than other people. Although some of our results supported that view, others did not. People with high narcissism scores were slightly more aggressive than other people toward someone who had praised them in Study 1 , but this effect was not replicated in Study 2 . Moreover, Study 2 added measures of displaced aggression, which is particularly relevant to the question of whether narcissists are aggressive in general. There were no significant correlations between narcissism and aggression toward a new, third person. Even if the narcissist had received an insulting evaluation from one person, he or she did not become exceptionally aggressive (i.e., any more than nonnarcissists) toward a different person.

Thus, our data suggest that aggression by narcissists is an interpersonally meaningful and specific response to ego threat. Narcissists became exceptionally aggressive toward a person who had given them a negative, insulting evaluation. They were not, generally, indiscriminately aggressive toward all other people or in all situations, nor did they show elevated tendencies to engage in displaced aggression. (That is, even receiving an insult did not make narcissists aggressive toward anyone except the person who delivered the insult.) Rather, our results suggest that narcissists mainly want to punish or defeat someone who has threatened their highly favorable views of themselves.

The present conclusions would be much broader if they suggested that all favorable views of self (i.e., high self-esteem per se) contributed to increased aggression. We did not find any such effect, however. Self-esteem yielded no significant main effects or interactions in either study.

Although nonsignificant findings are inherently difficult to interpret, we believe that our null results regarding self-esteem (combined with the rather surprising lack of other published findings on self-esteem and aggression) at least create serious doubt that self-esteem has any direct relation to aggression. We found significant effects for narcissism even when controlling for self-esteem, which suggests that the role of self-esteem is small at best. The null hypothesis that self-esteem is completely irrelevant to aggression cannot be confidently rejected on the basis of our data.

The failure of self-esteem to predict aggression in the present work cannot be attributed to a weakness in our measures of aggression, because we did find significant effects of other variables (narcissism, ego threat, sex, and aggression target) on those measures. It cannot be attributed to the timing of the selfesteem measure, because the two experiments administered the self-esteem measure at different times. It cannot be attributed to one specific self-esteem scale, because the two experiments used two different (indeed, quite different) scales.

Our results do dovetail with those of Kernis et al. (1989) to suggest that self-esteem, as measured by the Rosenberg scale, does not have any such direct link to aggression and that the most aggressive people are likely to be in one subset of individuals with highly favorable opinions of themselves. More generally, our results support the growing suspicion that high selfesteem is a heterogeneous category (e.g., Schneider \& Turkat, 1975). There are sound theoretical reasons for supposing that it is. High self-esteem is defined simply as having a favorable opinion or evaluation of oneself. This favorable view may be well founded in objective reality and may constitute an accurate appreciation of one's good traits, or it may be a highly dubious sense of personal superiority that is inflated well beyond what the facts would justify. It may be stable and largely impervious 
to evaluations by others, or it may demand frequent confirmation and validation by other people and be prone to fluctuate in response to daily events. This heterogeneity seems to undermine the usefulness of self-esteem per se for predicting aggression.

More generally, our results do not indicate that aggression flows directly from any form of self-regard. Neither a chronic pattern of low self-esteem nor a broadly favorable view of self produced high levels of aggression in either study. Even narcissism did not lead to elevated aggression overall; rather, the aggression of narcissists occurred mainly in direct response to criticism and insult.

We began this work with the hypothesis that threatened egotism would lead to aggression (Baumeister et al., 1996). In that connection, what does it mean to conclude that narcissism predicts aggression (in response to threat), whereas self-esteem does not? One way to answer this is to note that the concept of egotism has a dual meaning, and high self-esteem and narcissism capture the two different versions of it. High self-esteem means thinking well of oneself, whereas narcissism involves passionately wanting to think well of oneself. The present findings suggest that it is the latter (emotional and motivational) sense of egotism that is decisive for aggression. The preeminence of the emotional and motivational pattern was anticipated by Kernberg (1975), whose work on narcissism concluded by stating, "therefore, the ultimate nature of narcissism . . . is dependent upon the development of affect dispositions"' (pp. 340-341). Recent findings by Emmons (1987), Morf and Rhodewalt (1993), and Rhodewalt and Morf (in press) have likewise emphasized the affective aspect of narcissism, especially the proneness to feel angry and hostile in response to criticism.

In plainer terms, it is not so much the people who regard themselves as superior beings who are the most dangerous but, rather, those who have a strong desire to regard themselves as superior beings. Some people may be able to brush off criticism easily, just as others may view it as valid and well deserved, and neither response may produce aggression. In contrast, people who are preoccupied with validating a grandiose self-image apparently find criticism highly upsetting and lash out against the source of it. Thinking well of oneself is not inherently prone to lead to aggression--even in response to criticism and insults - but wanting to think well of oneself may well be.

\section{References}

Aiken, L. S., \& West, S. G. (1991). Multiple regression: Testing and interpreting interactions. Newbury Park, CA: Sage.

Anderson, C. A., \& Bushman, B. J. (1997). External validity of "trivial" experiments: The case of laboratory aggression. General Psychology Review, 1, 19-41.

Baron, R. A., \& Richardson, D. (1993). Human aggression. New York: Plenum.

Baumeister, R. F., Heatherton, T. F., \& Tice, D. M. (1993). When ego threats lead to self-regulation failure: Negative consequences of high self-esteem. Journal of Personality and Social Psychology, 64, 141156.

Baumeister, R. F., Smart, L., \& Boden, J. M. (1996). Relation of threatened egotism to violence and aggression: The dark side of high selfesteem. Psychological Review, 103, 5-33.

Berkowitz, L. (1989). Frustration-aggression hypothesis: Examination and reformulation. Psychological Bulletin, 106, 59-73.
Bernstein, S., Richardson, D., \& Hammock, G. (1987). Convergent and discriminant validity of the Taylor and Buss measures of physical aggression. Aggressive Behavior, 13, 15-24.

California Task Force to Promote Self-Esteem and Personal and Social Responsibility. (1990). Toward a state of self-esteem. Sacramento: California State Department of Education.

Cohen, J., \& Cohen, P. (1983). Applied multiple regression/correlation analysis for the behavioral sciences ( 2 nd ed.). Hillsdale, NJ: Erlbaum.

Dollard, J., Doob, L., Miller, N., Mowrer, O., \& Sears, R. (1939). Frustration and aggression. New Haven, CT: Yale University Press.

Emmons, R. A. (1984). Factor analysis and construct validity of the Narcissistic Personality Inventory. Journal of Personality Assessment, 48, 291-300.

Emmons, R. A. (1987). Narcissism: Theory and measurement. Journal of Personality and Social Psychology, 52, 11-17.

Fleming, J. S., \& Courtney, B. E. (1984). The dimensionality of selfesteem II: Hierarchical facet model for revised measurement scales. Journal of Personality and Social Psychology, 46, 404-421.

Geen, R. G. (1990). Human aggression. Pacific Grove, CA: Brooks/ Cole.

Giancola, P. R., \& Zeichner, A. (1995). Construct validity of a competitive reaction-time aggression paradigm. Aggressive Behavior, 21, 199-204.

Jaccard, J., Turrsi, R., \& Wan, C. K. (1990). Interaction effects in multiple regression. Newbury Park, CA: Sage.

Janis, I. L., \& Field, P. B. (1959). Sex differences in factors related to persuasibility. In C. I. Hovland \& I. L. Janis (Eds.), Personality and persuasibility (pp. 55-68, 300-302). New Haven, CT: Yale University Press.

Jöreskog, K. G., \& Sörbom, D. (1993). Windows LISREL 8.12. Chicago: Scientific Software.

Kernberg, O. (1975). Borderline conditions and pathological narcissism. New York: Jason Aronson.

Kernis, M. H. (1993). The roles of stability and level of self-esteem in psychological functioning. In R. Baumeister (Ed.), Self-esteem: The puzzle of low self-regard (pp. 167-182). New York: Plenum.

Kernis, M. H., Cornell, D. P., Sun, C. R., Berry, A., \& Harlow, T. (1993). There's more to self-esteem than whether its high or low: The importance of stability of self-esteem. Journal of Personality and Social Psychology, 65, 1190-1204.

Kernis, M. H., Grannemann, B. D., \& Barclay, L. C. (1989). Stability and level of self-esteem as predictors of anger arousal and hostility. Journal of Personality and Social Psychology, 56, 1013-1022.

Kirschner, D. (1992). Understanding adoptees who kill: Dissociation, patricide, and the psychodynamics of adoption. International Journal of Offender Therapy and Comparative Criminology, 36, 323-333.

Kohut, H. (1971). The analysis of the self. New York: International Universities Press.

Long, D. E. (1990). The anatomy of terrorism. New York: Free Press. Millon, T. (1981). Disorders of personality. New York: Wiley.

Morf, C. C., \& Rhodewalt, F. (1993). Narcissism and self-evaluation maintenance: Explorations in object relations. Personality and Social Psychology Bulletin, 19, 668-676.

Neter, J., Wasserman, W., \& Kutner, M. H. (1990). Applied linear statistical models (3rd ed.). Homewood, IL: Irwin.

Oates, R. K., \& Forrest, D. (1985). Self-esteem and early background of abusive mothers. Child Abuse and Neglect, 9, 89-93.

Raskin, R. N., \& Hall, C. S. ( 1979) . A narcissistic personality inventory. Psychological Reports, 45, 590.

Raskin, R., Novacek, J., \& Hogan, R. (1991). Narcissistic self-esteem management. Journal of Personality and Social Psychology, 60, 911918.

Raskin, R., \& Terry, H. (1988). A principal-components analysis of the Narcissistic Personality Inventory and further evidence of its construct 
validation. Joumal of Personality and Social Psychology, 54, 890902.

Rhodewalt, F., Madrian, J. C., \& Cheney, S. (1998). Narcissism, selfknowledge, organization, and emotional reactivity: The effect of daily experience on self-esteem and affect. Personality and Social Psychology Bulletin, 24, 75-87.

Rhodewalt, F., \& Morf, C. C. (1995). Self and interpersonal correlates of the Narcissistic Personality Inventory: A review and new findings. Journal of Research in Personality, 29, 1-23.

Rhodewalt, F., \& Morf, C. C. (1998). On self-aggrandizement and anger: A temporal analysis of narcissism and affective reactions to success and failure. Journal of Personality and Social Psychology, 74, 672685.

Rosenberg, M. (1965). Society and the adolescent self-image. Princeton, NJ: Princeton University Press.

Schneider, D. J., \& Turkat, D. (1975). Self-presentation following success and failure: Defensive self-esteem models. Journal of Personality, 43, 127-135.

Schoenfeld, C. G. (1988). Blacks and violent crime: A psychoanalytically oriented analysis. Journal of Psychiatry and Law, 16, 269-301.

Tangney, J. P. (1995). Shame and guilt in interpersonal relationships.
In J. Tangney \& K. Fischer (Eds.), The self-conscious emotions (pp. 114-139). New York: Guilford Press.

Tangney, J. P., Wagner, P. E., Fletcher, C., \& Gramzow, R. (1992). Shamed into anger? The relation of shame and guilt to anger and selfreported aggression. Journal of Personality and Social Psychology, 62, 669-675.

Taylor, S. P. (1967). Aggressive behavior and physiological arousal as a function of provocation and the tendency to inhibit aggression. Journal of Personality, 35, 297-310.

Tedeschi, J. T., \& Felson, R. B. (1994). Violence, aggression, and coercive actions. Washington, DC: American Psychological Association.

Watson, P. J., Grisham, S. O., Trotter, M. V., \& Biderman, M. D. (1984). Narcissism and empathy: Validity evidence for the Narcissistic Personality Inventory. Journal of Personality Assessment, 48, 301-305.

Wiehe, V. R. (1991). Perilous rivalry: When siblings become abusive. Lexington, MA: Heath/Lexington Books.

Wink, P. (1991). Two faces of narcissism. Journal of Personality and Social Psychology, 61, 590-597.

Received February 18, 1997

Revision received June 23, 1997

Accepted October 2, 1997 